\title{
O OBSERVADOR DOS PANORAMAS E O FLÂNEUR: REFLEXÃO SOBRE A OBRA PARIS, A CAPITAL DO SÉCULO XIX DE WALTER BENJAMIN
}

Autora: Paula Tárcia Fonteles Silva José Expedito Passos Lima

\begin{abstract}
RESUMO
O presente artigo tratará sobre o observador dos panoramas e o flâneur, na obra intitulada Paris, a capital do século XIX, de Walter Benjamin. Neste escrito, Benjamin apresenta os aspectos da industrialização e da história social urbana, explicitando os comportamentos sociais e a questão das mercadorias como sonho coletivo, que o capitalismo do século XIX produziu, não obstante o caráter fetichizante desta sociedade. Assim, abordaremos a distinção entre o observador dos panoramas, aquele que percebe a cidade apenas como paisagem a ser reverenciada, apresentando-se apenas como mais um participe do jogo de ilusões da vida burguesa, enquanto o flâneur, além de ser observador, tem por característica ser aquele habitante que vive, sente e estabelece relações mais diretas e incisivas com a cidade.
\end{abstract}

Palavras-chave: Flâneur, panorama, fetichismo, Paris, capital do século XIX.

\section{THE OBSERVER PANORAMA AND THE FLÂNEUR: REFLECTION ON THE WORK PARIS, THE CAPITAL OF THE NINETEENTH CENTURY WALTER BENJAMIN}

\begin{abstract}
This article will deal on the observer panoramas and flâneur, the work entitled Paris, the capital of the nineteenth century, Walter Benjamin. At this writing, Benjamin presents aspects of industrialization and urban social history, explaining the social behavior and the issue of goods as a collective dream, that capitalism of the nineteenth century produced, despite the fetishism character of this society. Thus, we discuss the distinction between observer of panoramas, who realizes just how the city landscape to be revered, appearing only as a performer of the game of illusions of bourgeois life, while the flâneur, besides being an observer, is characteristic is that local living, feel and establishes relationships with more direct and incisive with the city.
\end{abstract}

Keywords: Flâneur, panorama, fetishism, Paris, the capital of the nineteenth century. 
Para abordar a reflexão de Walter Benjamin acerca do desenvolvimento capitalista na modernidade, o presente trabalho considera os seus escritos Paris capital do século XIX e Paris no segundo império em Baudelaire. Na sua exposição, Benjamin destaca, nos escritos aqui considerados, os seguintes tópicos: "Paris, a capital do século XIX" em i) Fourier ou as passagens; ii) Daguerre ou os panoramas; iii) Grandville ou as exposições universais; iv) Luís Filipe ou o intérieur; v) Baudelaire ou as ruas de Paris e vi) Haussmann ou as barricadas. O segundo escrito, "Paris do Segundo Império em Baudelaire" se divide em três fragmentos: i) a Boêmia ii) o Flâneur e iii) a Modernidade.

Benjamin se reporta a Paris do século XIX com o intento de apreender a modernidade do capitalismo no seu momento mais significativo. Daí destacar a questão da metrópole e o processo de modernização, identificando as suas consequências junto a cidade e os seus habitantes, a cultura, a arquitetura, a moda e a arte. Portanto, com a modernização das cidades, todo o ethos se modificou. Benjamin busca interpretar o estado da cultura na época de uma Modernidade em processo de expansão. No seu entender:

(...) da vida burguesa que estabeleceu na França... Tudo passava em desfile... Dias de festa e dias de luto, trabalho e lazer, costumes matrimoniais e hábitos celibatários, famílias, casa, filhos, escola, sociedade, teatro, tipos, profissões ${ }^{1}$.

$\mathrm{Na}$ obra Passagens, Benjamin apresenta o processo de modelação das metrópoles modernas com base na produção industrial. Ele demonstra como a burguesia mobiliza o proletariado em torno do fetiche, visto que o embelezamento da cidade acaba por inibir o avanço do proletariado na luta de barricadas, apresentando falsos benefícios do modo de vida burguês. Sobre isso, Engels já alertava das consequências e dos impactas do modo de vida burguês sobre o indivíduo e sobre a comunidade, ao afirmar que:

Essas centenas de milhares de pessoas, de todos os Estados e de todas as
classes, que se apressam e se empurram, não serão todas seres humanos,
possuindo as mesmas qualidades e capacidades e o mesmo interesse na
procura da felicidade? E não deverão, enfim, procurar a felicidade com os

1 BENJAMIN, Walter. Obras escolhidas III - Charles Baudelaire um Lírico no Auge do Capitalismo. Trad. José Carlos Martins Barbosa e Hemerson Alves Baptista. São Paulo: Brasiliense, 1989. p. 34. 
mesmos métodos e processos? E, contudo, essas pessoas cruzam-se apressadas, como se nada tivessem em comum, nada a realizar juntas, e a única convenção entre elas é o acordo tácito pelo qual cada um ocupa a sua direita no passeio, afim de que as duas correntes de multidão que se cruzam não se constituam mutuamente obstáculo; e contudo, não vem ao espírito de ninguém conceder ao outro um olhar sequer. Essa indiferença brutal, esse isolamento insensível de cada indivíduo no seio de seus interesses particulares são tanto mais repugnantes e chocantes quanto maior é o número de indivíduos confinados neste reduzido espaço. E mesmo quando sabemos que esse isolamento do indivíduo, esse egoísmo mesquinho, é em toda parte o princípio fundamental da sociedade atual, em parte alguma ele se manifesta com uma impudência, uma segurança tão completa como aqui, precisamente, na confusão da grande cidade ${ }^{2}$

Benjamin, por sua vez, em sua reflexão sobre os aspectos da industrialização e da história social urbana, explicita os comportamentos sociais e a questão das mercadorias como sonho coletivo, que o capitalismo do século XIX produziu, não obstante o caráter fetichizante desta sociedade. Tal fantasmagoria moderna, gerada pelas mercadorias reenvia, igualmente, à publicidade, às arquiteturas e às práticas sociais. Dessa forma, as imagens do flâneur são típicas do cenário urbano de Paris e essenciais para o autor exprimir concretamente uma constelação históricofilosófica própria da Modernidade. A fantasmagoria da mercadoria revela que ela não poderá nunca ser simplesmente objeto (de uso ou de troca), pois the é inerente um poder que a põe em uma esfera separada que alcança o dito "inconsciente coletivo". Ao valor de uso e ao valor de troca, Benjamin acrescenta aquilo que podemos definir "valor de exposição".

A sua compreensão, nesse escrito, revela que a Modernidade, precisamente aquela inscrita no século XIX, transformou não só a paisagem, mas o sentimento dos habitantes desta cidade que se propunha a abarcar o mundo. Dentre as fantasmagorias do espaço e da natureza, muito próprias aos anseios da Modernidade, pode-se destacar as "passagens" e os "panoramas". As passagens foram as "casas" e, ao mesmo tempo, foram as "ruas" visitadas por esse habitante de olhar ambulante, em especial, o flâneur, os panoramas, por sua vez, por terem acolhido em seu interior o mundo que era em forma de caixa cercada de pinturas.

Os panoramas, oriundos da técnica de imitação da natureza pela pintura, com a ajuda dos recursos luminosos e ruídos, foram um entretenimento para espectador

2 ENGELS. A situação da classe trabalhadora na Inglaterra. Trad. Rosa Camargo Artigas e Reginaldo Forti. Rio de Janeiro: Global, 1985, p. 35-36. 
que tornou algo, com efeito ilusório. Tal diz respeito à fantasmagoria, se refere ainda à inclusão da natureza, das paisagens e das cenas estrangeiras na cidade, algo que revela o empenho de transformar aquilo que é ilusão em algo real e que, ao mesmo tempo, encobre a totalidade do espaço. Conforme Benjamin:

Foi incansável o esforço de tornar os panoramas, por meio de artifícios técnicos, locais de uma imitação perfeita da natureza. Procurava-se reproduzir na paisagem as mudanças da luz do dia, o nascer da lua, o murmurar das cascatas. David aconselha seus discípulos a desenharem os panoramas segundo a natureza. Ao tentar reproduzir na natureza representada as transformações de maneira enganosamente similar, os panoramas abrem o caminho, para além da fotografia, ao cinema mudo e ao cinema sonoro ${ }^{3}$.

Benjamin demonstra o empenho em reproduzir as mudanças às luzes nas paisagens, uma clara tentativa de representar o nascer do dia. Além disso, outros exemplos podem aqui ser inferidos, como é o caso da tentativa de reprodução do murmurinho das cascatas, fato este que contribuiu para a constituição daquilo que em seguida surgiria abrindo caminho para uma relação da arte com a técnica, algo que causará um novo sentimento de vida nos habitantes da cidade, revelando a tentativa de se inserir o campo na cidade. De acordo com Benjamin:

Os panoramas, que anunciam uma revolução nas relações da arte com as técnicas, são ao mesmo tempo expressão de um novo sentimento de vida. O habitante da cidade, cuja superioridade política em relação ao morador do campo se manifesta inúmeras vezes no decorrer do século, tenta inserir o campo na cidade. Nos panoramas, a cidade amplia-se, transformando-se em paisagem, como fará mais tarde e de maneira mais sutil para flâneur ${ }^{4}$.

Com isso, Benjamin identifica na obra de Charles Baudelaire (1821- 1867), uma "consciência de crise". No seu entender, Baudelaire ${ }^{5}$ exprime em sua obra o prazer ao podre, à destruição e a beleza do mal, uma celebração da rebeldia secreta da burguesia contra a sua própria classe: algo que se apresenta como um protesto "secreto" para Benjamin. Sobre as obras de Baudelaire, Olgária Matos afirma que:

${ }^{3}$ BENJAMIN. Passagens. Belo Horizonte: Editora UFMG; São Paulo: Imprensa Oficial do Estado de São Paulo, 2006.p.42.

4 Ibidem

5 De acordo com Kothe: $O$ engenho de Baudelaire, nutrindo-se da melancolia, é alegórico. Pela primeira vez, com Baudelaire, Paris se torna objeto da poesia lírica. Essa poesia não é nenhuma arte nacional e familiar: pelo contrário, o olhar alegórico a passar a cidade é o olhar do estranhamento. É o olhar do flâneur, cuja forma de vida envolve um halo conciliador a desconsolada forma da vida vindoura do homem da cidade grande. KOTHE.(Org.). Walter Benjamin. Sociologia. São Paulo: Ática, 1991, pp. 38-39. 
Vê-se com dificuldade a vantagem de atribuir a sua obra um lugar entre os bastiões avançados da liberação humana. Parece, antes de mais nada, muito mais promissor segui-lo nas maquinações lá onde ele se encontra, sem dúvida, no seu terreno: no inimigo. Suas maquinações só raramente se voltam com vantagens para o inimigo. Baudelaire era um agente secreto, um agente do descontentamento secreto de sua própria classe e lugar de sua própria dominação. Extrai-se mais de Baudelaire confrontando-o com sua classe do que rejeitando-o como desinteressante do ponto de vista do proletariado ${ }^{6}$.

É com Baudelaire que Paris, pela primeira vez, é objeto de poesia lírica, todavia, não em forma de poesia cantada para a cidade natal, mas na forma alegórica sobre a cidade. Baudelaire, quando põe Paris em sua poesia, lança o olhar do homem sobre a cidade em que se sente como estranho. Conforme comenta Benjamin: "trata-se do olhar do flâneur, cujo modo de vida dissimula ainda com um halo conciliador o futuro modo sombrio dos habitantes da grande cidade" 7 . O flâneur ainda está no limite tanto da burguesia quanto da grande cidade, pois procura um amparo na multidão. Sobre o flâneur, Baudelaire afirma:

\begin{abstract}
A multidão é o véu através do qual a cidade familiar acena para o flâneur como fantasmagoria. Nela, a cidade é ora paisagem, ora sala acolhedora. Ambas são aproveitadas na configuração das lojas de departamentos, que tornam o próprio flanar proveitoso para a circulação das mercadorias. A loja de departamentos é a última passarela do flâneur .

Agora, à hora em que os outros estão dormindo, ele está curvado sobre sua mesa, lança sobre sua folha de papel o mesmo olhar que há pouco dirigia às coisas, lutando com seu lápis, sua pena, seu pincel, lançando água do copo até o teto, limpando a pena na camisa, apressado, violento, ativo, como se temesse que as imagens Ihe escapassem, belicoso, mas sozinho e debatendo-se consigo mesmo. $\mathrm{E}$ as coisas renascem no papel, naturais e, mais do que naturais, belas; mais do que belas, singulares e dotadas de uma vida entusiasta como a alma do autor. A fantasmagoria foi extraída da natureza. Todos os materiais atravancados na memória classificam-se, ordenam-se, harmonizam-se e sofrem essa idealização forçada que é o resultado de uma percepção Infantil, isto é, de uma percepção aguda, mágica à força de ser ingênua! ${ }^{9}$
\end{abstract}

6 MATOS. A Escola de Frankfurt luzes e sombras do iluminismo. São Paulo: Moderna, 1993.p. 111.

7 BENJAMIN. Passagens. Belo Horizonte: Editora UFMG; São Paulo: Imprensa Oficial do Estado de São Paulo, 2006.p.47.

8 Ibidem.

9 BAUDELAIRE. O pintor da vida moderna. In: A modernidade de Baudelaire. Rio de Janeiro: Paz e Terra,1988, p. 173.

Paula Tárcia Fonteles Silva - Mestranda em Filosofia pela Universidade Estadual do Ceará (CMAF/UECE). Brasileira, residente em Fortaleza - CE, E-mail: paulatarcia@ hotmail.com 
O passear do flâneur pela cidade de Paris, por ainda não ter ruas largas, uma vez que as transformações urbanísticas realizadas por Haussmann ${ }^{10}$ ainda não tinham sido executadas, só pôde se realizar em sua plenitude, ao se ver nas galerias, passagens revestidas por vidros, cobertas de mármore que protegiam os estabelecimentos comerciais. Tais galerias "são um meio-termo entre a rua e o interior da casa". Por isso Benjamin considera que:

A rua se torna moradia para o flâneur que, entre as fachadas dos prédios, sente-se em casa tanto quanto o burguês entre suas quatro paredes. Para ele, os letreiros esmaltados e brilhantes das firmas são um adorno de parede tão bom ou melhor que a pintura a óleo no salão do burguês; muros são a escrivaninha onde apóia o bloco de apontamentos; bancas de jornais são suas bibliotecas, e os terraços dos cafés, as sacadas de onde, após o trabalho observa o ambiente ${ }^{11}$.

Para Benjamin, o flâneur tinha uma visão do mundo em forma de miniatura, uma vez que a fisiologia deste se transformou em bulevares, ao passo que se distancia de qualquer visão perigosa da cidade e dos seus habitantes. Sendo assim a vida dos parisienses podia se realizar agora sob o jugo da fantasmagoria, uma vez que esses lugares produziam uma visão restrita e inofensiva da grande cidade, onde ninguém estava isento do tumulto, da competitividade e da disputa de interesses. Dessa forma, os fisiologistas perderam o seu lugar e no espaço que anteriormente se encontravam, encontra-se a literatura, igualmente popularesca que tinha por objeto a preocupação com os perigos da vida urbana na nova metrópole, assim o gênero mais difundido era aquele que envolvia os romances policiais.

O flâneur se tornará, quase que sem querer, um detetive. A sua desocupação fazia com que essa tarefa fosse adequada, vinculando-se ao seu olhar sempre vigilante: algo que o fazia seguir os vestígios dessa trama e solucionar os delitos descritos. De acordo com Benjamin, "se compreende como o romance policial, a despeito de seu sóbrio calculismo, também colabora na fantasmagoria da vida

${ }^{10}$ Cf. BENJAMIN. Passagens. Belo Horizonte: Editora UFMG; São Paulo: Imprensa Oficial do Estado de São Paulo, 2006. Com a "haussmanização", sob o domínio de Napoleão III, os citadinos sentemse alienados pelo apogeu do capitalismo. Haussmann faz surgir a especulação fraudulenta de modo que a população proletária, pelo forte aumento dos aluguéis, é impelida para os subúrbios. Conhecido como artista demolidor causa o estranhamento da cidade nos parisienses. Eles não se sentem mais na cidade como em sua própria casa. Os bairros não parecem ter mais uma própria fisionomia. É despertada uma consciência de que a cidade é desumana.

${ }^{11}$ BENJAMIN. Obras escolhidas III - Charles Baudelaire um Lírico no Auge do Capitalismo. Trad. José Carlos Martins Barbosa e Hemerson Alves Baptista. São Paulo: Brasiliense, 1989.p. 35. 
parisiense" ${ }^{12}$. Tais aventuras policiais passam a ser uma visão da vida de Paris: algo que descreve a cidade como um local onde deve-se sempre estar a postos para alcançar um criminoso.

No contexto em que as aventuras policiais são largamente difundidas, 0 intérieur aparece como puramente burguês, em suas várias formas, sendo este um sustentáculo das ilusões do modo de vida burguês. Nesse sentido, o "intérieur não apenas é universo, mas também o invólucro do homem privado" ${ }^{13}$. O intérieur remove de seus objetos o caráter de mercadoria, passando assim a lhe conferir um valor afetivo. Essa permuta substitui o valor de uso ou de utilidade, por outro, a saber, aquele de afeto: algo próprio do colecionador. Daí Benjamin afirmar sobre o intérieur:

(...) $O$ colecionador é verdadeiro habitante intérieur. (...) O colecionador sonha em alcançar não apenas um mundo longínquo ou passado - porém, ao mesmo tempo melhor, no qual os homens, na verdade, estão tão pouco providos daquilo de que necessitam como no mundo cotidiano -, mas também um mundo em que as coisas estão liberadas da obrigação de serem úteis ${ }^{14}$.

No intérieur todos os vestígios encontram-se resguardados em uma morada reservada e, que apenas o colecionador tem acesso, remontando a uma espécie de mundo privado em que os seus objetos estocados em locais sempre bem protegidos, conferem à sua casa um caráter ainda mais particular. Dessa maneira a história do detetive ocorre como meio de investigação desses rastros, incumbido de desvendar as particularidades das vidas privadas. Daí os primeiros fisiognomonistas do intérieur já apresentarem em seus romances, os criminosos enquanto partícipes da burguesia. ${ }^{15}$.

Dessa forma, uma dupla característica passa a ser conferida à cidade: ao mesmo tempo em que ela se revela de maneira ilimitada para o flâneur, ela, igualmente, se encobre resguardando o seu interior. Cada passagem da cidade apresenta-se assim como uma miniatura do mundo, tendo como característica a

\footnotetext{
${ }^{12}$ Ibidem, p.39.

${ }^{13}$ BENJAMIN. Passagens. Belo Horizonte: Editora UFMG; São Paulo: Imprensa Oficial do Estado de São Paulo, 2006. p. 46.

${ }^{14}$ BENJAMIN. Passagens. Belo Horizonte: Editora UFMG; São Paulo: Imprensa Oficial do Estado de São Paulo, 2006. p.46.

${ }^{15}$ Cf. BENJAMIN; Passagens. Belo Horizonte: Editora UFMG; São Paulo: Imprensa Oficial do Estado de São Paulo, 2006. p. 46.
} 
forma de fantasmagoria. Por isso Benjamin sustenta que "o fenômeno da rua como interior, fenômeno em que se concentra a fantasmagoria do flâneur, é difícil de separar da iluminação a gás. As primeiras lâmpadas a gás arderam nas galerias ${ }^{16 "}$.

Posteriormente, em meados do século XIX, a galeria progressivamente perde o seu lugar de privilegio na vida cotidiana, apresenta-se como atrasada frente o surgimento da luz elétrica. As grandes lojas passam a ser o local privilegiado do flâneur, ocupando o seu tempo e determinando o seu ócio. Todavia, a modificação desse flanar se revela, na medida em que decai aquele antigo encanto, ou seja, do caminhar vagarosamente pelas passagens, pois aquele invólucro que anteriormente encobrira as mercadorias nas passagens decai nas grandes lojas, tornando aparente apenas as mercadorias, destituindo o encanto de um local anterior. Agora tudo passara a ser visível para o flâneur. De acordo com Benjamin:

A flâneurie caiu de moda e mesmo a luz de gás já não se tinha como elegante, o derradeiro flâneur a vagar tristemente pela Passage Colbert teve a impressão de que o chamejar dos bicos de gás apenas exibia o medo de chama de não ser paga ao final do mês ${ }^{17}$.

Apresenta-se aqui a distinção essencial entre o flâneur e o observador: o primeiro é aquele caminhante das galerias, o segundo diz respeito ao observador dos panoramas. Pode-se inferir que enquanto o flâneur encontra-se entre a rua e a casa, o observador dos panoramas se vincula ao espetáculo panorâmico, associando a sua experiência àquela ilusória, dissociada de uma relação direta entre aquele que observa e a cidade observada. Dessa maneira, a cidade apresenta-se ela mesma como uma ilusão, repleta de fantasmagorias, objeto totalmente estranho, para o observador de panoramas. O flâneur, por sua vez, tem a sua vivência ainda vinculada às ruas e às galerias desta cidade. Daí Bolle argumentar que o flâneur apresenta-se como uma "figura contraditória ao espírito de seu tempo, o flâneur se torna, na sociedade burguesa, uma espécie ameaçada de extinção" ${ }^{18}$, sendo assim,

\footnotetext{
${ }^{16}$ BENJAMIN; Obras escolhidas III - Charles Baudelaire um Lírico no Auge do Capitalismo. Trad. José Carlos Martins Barbosa e Hemerson Alves Baptista. São Paulo: Brasiliense, 1989.p. 47.

${ }^{17}$ BENJAMIN. Obras escolhidas III - Charles Baudelaire um Lírico no Auge do Capitalismo. Trad. José Carlos Martins Barbosa e Hemerson Alves Baptista. São Paulo: Brasiliense, 1989. p. 47.

${ }^{18}$ BOLLE, Fisiognomia da Metrópole Moderna: representação da história em Walter Benjamin. São Paulo: EDUSP, 1994, p. 375.
} 
a "ociosidade do flâneur é um protesto contra a divisão de trabalho -, porém, inutilmente; ele acaba tendo que se curvar diante das leis da economia capitalista"19.

Destaca-se que o flâneur, ainda que se utilize de um modo panorâmico de observação da cidade, não tem como única característica seu olhar. Com isso, o "flâneur é, por definição, um ser dotado de imensa ociosidade e que pode dispor de uma manhã ou tarde para zanzar sem direção" ${ }^{20}$, antes de tudo, o flâneur é marcado por um "excesso de ética produtiva (ou um desejo de tudo ver e de encontrar todo mundo que conta) inibe o espírito farejador e a ambição deambulante de 'esposar a multidão"21.

Desse modo, sua vivência na cidade o distingue daquele que meramente a observa. Com isso ele se distingue da multidão pelo fato de não ter qualquer encanto pelas mercadorias, pois a cidade é seu lugar e sua vivência: algo imprescindível. Ainda que ambos estejam imersos na mesma cidade, o observador dos panoramas tende sempre a naturalizar, quer a cidade quer as relações nelas constituídas, ao passo que o flâneur tem em si um olhar de estranhamento sobre a cidade e naquilo que se transformou. Ainda sobre isso, Massagli afirma que o flâneur:

É o leitor da cidade, bem como de seus habitantes, através de cujas faces tenta decifrar os sentidos da vida urbana. De fato, através de suas andanças, ele transforma a cidade em um espaço para ser lido, um objeto de investigação, uma floresta de signos a serem decodificados - em suma, um texto ${ }^{22}$.

É por ter um modo particular de vivenciar e perceber a cidade que o flâneur não se encontra arrebatado pela ilusão desta, ou mesmo, pela ilusão do mundo das mercadorias. Por meio dessa relação que ele estabelece com a rua, é que se o pode diferenciar. Conforme Benjamin:

De ambos os lados dessas vias se estendem os elegantes estabelecimentos comerciais, de modo que uma de tais paisagens é como uma cidade, um mundo em miniatura. Nesse mundo o flâneur está em casa,

\footnotetext{
${ }^{19}$ Ibidem.

${ }^{20}$ WHITE. O flâneur: um passeio pelos paradoxos de Paris. São Paulo: Companhia das Letras, 2001, p. 48.

21 Ibidem, p. 49.

${ }^{22}$ MASSAGLI; "Homem da multidão e o flâneur no conto 'O homem da multidão' de Edgar Allan Poe". Terra roxa e outras terras, v. 12, p. 55-65, jun. 2008 . Disponível em: $<$ www.uel.br/pos/letras/terraroxa/g_pdf/vol12/TRvol12f.pdf> Acesso em: 01 jun. 2014.
} 
é graças a ele essa paragem predileta dos passeadores e dos fumantes, esse picadeiro de todas as pequenas ocupações imagináveis ${ }^{23}$.

Pode-se ainda considerar que o observador dos panoramas, ao perceber a cidade apenas como paisagem a ser reverenciada, apresenta-se apenas como mais um participe do jogo de ilusões da vida burguesa: algo característico de um modo apassivado de vivenciar as coisas. Ele é apenas mais um espectador na grande platéia de um espetáculo horrendo. O flâneur, por sua vez, além de ser observador, tem por característica ser aquele habitante que vive, sente e estabelece relações mais diretas e incisivas com a cidade, pois ele não a tem apenas como uma paisagem, mas antes de tudo, se vê como partícipe desta.

${ }^{23}$ BENJAMIN. Obras escolhidas III - Charles Baudelaire um Lírico no Auge do Capitalismo. Trad. José Carlos Martins Barbosa e Hemerson Alves Baptista. São Paulo: Brasiliense, 1989.p. 35. 


\section{REFERÊNCIAS}

BAUDELAIRE, Charles. O pintor da vida moderna. In: A modernidade de Baudelaire. Rio de Janeiro: Paz e Terra,1988.

BENJAMIN, Walter. Obras escolhidas III - Charles Baudelaire um Lírico no Auge do Capitalismo. Trad. José Carlos Martins Barbosa e Hemerson Alves Baptista. São Paulo: Brasiliense, 1989.

. Passagens. Belo Horizonte: Editora UFMG; São Paulo: Imprensa Oficial do Estado de São Paulo, 2006.

BOLLE, Willi. Fisiognomia da Metrópole Moderna: representação da história em Walter Benjamin. São Paulo: EDUSP, 1994.

ENGELS, F. A situação da classe trabalhadora na Inglaterra. Trad. Rosa Camargo Artigas e Reginaldo Forti. Rio de Janeiro: Global, 1985.

KOTHE, Flávio René. (org.). Walter Benjamin. Sociologia. São Paulo: Ática, 1991 MASSAGLI, Sérgio Roberto. Homem da multidão e o flâneur no conto 'O homem da multidão' de Edgar Allan Poe. Terra roxa e outras terras, v. 12, p. 55-65, jun. 2008. Disponível em: <www.uel.br/pos/letras/terraroxa/g_pdf/vol12/TRvol12f.pdf> Acesso em: 01 jun. 2014.

MATOS, Olgária. A Escola de Frankfurt luzes e sombras do iluminismo. São Paulo: Moderna, 1993.

WHITE, Edmund. O flâneur: um passeio pelos paradoxos de Paris. São Paulo: Companhia das Letras, 2001, p. 48. 